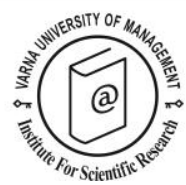

\title{
Are there economic benefits from marine protected areas? An analysis of scuba diver expenditure
}

\author{
Melville Saayman ${ }^{1 *}$ and Andrea Saayman ${ }^{2}$
}

Received: 03/04/2017 Accepted: 25/11/2017

\footnotetext{
1 Tourism Research in Economic Environs and Society (TREES), North-West University, Private Bag X6001, Potchefstroom 2520, South Africa. Tel: +27 (0)18 299 1810, Email:melville.saayman@nwu.ac.za

2 School of Economics, North-West University, Private Bag X6001, Potchefstroom 2520, South Africa. Tel: +27 (0)18 299 1443, Email: andrea.saayman@nwu.ac.za

* Corresponding author
}

\begin{abstract}
In 1998, the Italian authorities declared the marine area around the Peninsula of Portofino, Liguria, a Marine Protected Area (MPA) covering $13 \mathrm{~km}$ of coastline on the north-western coast of Italy. Thus, many feared decreased local tourism and resultant economic loss due to limitations on activities within the MPA. The MPA has, however, led to an increase in scuba in the area. This research evaluates the importance of scuba divers as a source of tourism and income for the local economies surrounding the Portofino MPA. Research indicates that spending is a better criterion for analysis than numbers of visitors to an attraction or area. Therefore, understanding spending behaviour is important in influencing the benefits derived from scuba diving tourism. While scuba diving is a popular activity worldwide and a drawcard for many destinations, little research analysing their spending behaviour is available. This research was conducted at the Portofino MPA, Italy, where more than 700 questionnaires were completed during June/July 2016 with the assistance of eight of approximately 20 diving operators in the area. The results provide dive operators and the destination marketing organisation with information on specific market segments and insight into the spending behaviour of divers.
\end{abstract}

(C) 2018 Varna University of Management. All rights reserved

Keywords: spending behaviour, Portofino, diving tourism, scuba diving

Citation: Saayman, M., and A. Saayman (2018) Are there economic benefits from marine protected areas? An analysis of scuba diver expenditure. European Journal of Tourism Research 19, pp. 2339

\section{Introduction}

Marine ecotourism is regarded by Sakellariadou (2014) as a rapidly growing and very profitable market of the tourism industry, which according to the author, also includes scuba diving as an activity. A large percentage of marine ecotourism activities take place in Marine Protected Areas (MPAs). A marine protected area is a clearly defined geographical space, recognised, dedicated and managed through legal or other effective means to achieve long-term conservation of nature with 
varied ecosystems and cultural values (Dudley, 2008).

These areas have many benefits, which is why, in the European Union (EU) alone, nearly 8000 sites are covering an area of $338623 \mathrm{~km}^{2}$, that is, $5.9 \%$ of EU waters (Russi et al., 2016). These benefits include the following: marine protected areas generate food; they contribute to mitigating climate change, create tourism and recreation opportunities; aid coastal security since they help to stabilise sediments and reduce erosion; they stimulate the local and regional economies where new and different markets are established, for example, visitors buy local food, drink, and souvenirs, while they stay in local hotels and other accommodation establishments. Developing MPAs also leads to improved infrastructure development in towns or regions where they are found as well as job creation and keeping or attracting young people to a region that is rapidly ageing. The MPAs therefore not only help a town or region to remain competitive and protect and conserve ecosystems and the marine environment, but also offer researchers opportunities to conduct research, and lend opportunities to educate and train people (Russi et al., 2016; Sakellariadou, 2014).

According to Cini and Saayman (2014), it is clear that governments cannot maintain protected areas on their own. In fact, grants for protected areas are decreasing rather than increasing. MPAs are therefore becoming more reliant on other sources of income. One of the key factors or role-players making a significant economic contribution is the tourist, specifically through their expenditure.

Economic analysis of tourism is increasingly important to tourism planning, marketing and policy formulation and is particularly useful for increasing the recognition of the economic value of national and marine parks and how to manage them (Catlin, Jones, Norman \& Wood, 2010; Tyrell \& Johnston, 2006; Wood \& Glasson, 2006). This raises the question, what are the economic contribution of an MPA; specifically when one starts to analyse activities taking place in these areas. Johnson and Moore (1993) state that providing figures for the total expenditure of tourists who visit a national park, for instance, may overestimate the economic impact of that particular park. They argue that it is more important to determine the expenditure that would be lost if that park or activity did not exist or when activities are ceased.

Stynes and White (2006) add that a more accurate view of the economic impact can be gained if various spending categories are assessed and when visitors are divided into distinct segments. Saayman and Saayman (2012) state that determining the items on which tourists, in this case, scuba divers, spend their money is paramount since this is more useful in determining leakages. With many MPAs situated in rural areas, one of the key threats to sustainable economic development is the magnitude of leakages from these regions.

Understanding spending behaviour can limit leakages and increase the economic impact to ensure that the local economy grows through scuba diving tourism. Their participation in different activities, the magnitude of their spending and the items that they spend their money on is becoming increasingly important from a sustainability point of view.

Therefore, the purpose of this paper is to evaluate the importance of scuba divers as a source of tourism and income for the local economies surrounding the Portofino MPA in Italy. This is done by considering the following questions: (i) on what do divers spend money? (ii) What influence their spending decision? (iii) How can the tourism industry benefit from them, especially in resorts where divers seemingly have a significant impact? (iv) Are there specific segments of divers that are more worthwhile to pursue than others? The Portofino MPA was chosen because, since its establishment in 1998, it has become one of Europe's best-known scuba diving destinations.

The next section will report on the relevant literature, followed by the method of research, results, findings and implications, and the conclusion.

\section{Literature review}

Scuba diving tourism can be defined as travel with the primary purpose to participate actively 
or passively in scuba diving activities. These activities may include scuba diving itself, attending shows and exhibitions and other scuba events, for example (Du Plessis \& Saayman, 2017). Globally more than 10000 dive operators are serving more than 6 million divers; hence it is an activity that has a significant economic value.

Leeworthy, Bowker, Hospital and Stone (2005) indicated that the US alone has 3,34 million divers and that the scuba diving industry is worth US\$ 2,6 billion (Graefe \& Todd, 2001). These researchers indicated that divers have a daily expenditure of between US $\$ 100$ and US\$200. Schuhmann, Casey and Oxenford (2008) found that scuba diving in Barbados attracts between 30000 and 50000 divers, and if each diver participates in one dive per visit, it creates an additional economic benefit that could be as high as US\$306 000. A study conducted by Saayman and Seymour (2012) at Sodwana Bay in South Africa revealed that the direct spend of divers contributes approximately US $\$ 30$ million to the local economy. Harriott (2002) found that approximately 1,6 million tourists travel to the Great Barrier Reef in Australia and they generate over $\$ 1$ billion. Wilks and Davis (2000) indicated that approximately 1 million of those visitors to the Great Barrier Reef are scuba divers. Based on these studies, it is clear that there are economic benefits that can be derived from scuba diving activities. However, it is also important to understand what products and services divers spend money on since the linkages between different industries differ and this influence the magnitude of the benefit.

One way to critically analyse the expenditure patterns of scuba divers is through expenditure-based segmentation. This is one of the most successful segmentation approaches available, and it is based on the notion that some markets are more lucrative to pursue than other markets. In fact, Legoherel (1998) stresses that expenditure-based segmentation may often be superior to other segmentation approaches since it offers planners, marketers and policy-makers significant benefits, including:

- high yielding markets can be identified;
- obtaining more detailed spending information;

- understanding the spending behaviour of scuba divers;

- offers useful information for policy formulation;

- helps in identifying niche markets;

- increased cost-effectiveness

of

marketing;

- ability to report on market changes and needs; and

- assists with developing the right package and better product development decisions (Saayman \& Saayman, 2006, 2012; Wilton \& Nickerson, 2006).

Market segmentation, according to Ekonomou, Neofitou and Matsiori (2014), and Park and Yoon (2009) is justified on the grounds of achieving greater efficiency in the supply, promotion and delivery of purpose designed products and services based on the demand and needs of different target markets in order to be more cost-effective in the marketing process. Segmentation effectiveness is based on segments of being measurable, accessible, substantial, actionable and differentiable. Segmentation can also be seen as the cornerstone of an effective marketing strategy, and it is the first step in formulating an effective marketing plan (Sung, Morrison \& O'Leary, 2000).

In the tourism literature (see for example Craggs \& Schofield, 2006, and Kruger, Saayman \& Saayman, 2010), many approaches or variables have been used in the segmentation of markets. However, when it comes to identifying more lucrative markets or markets with the highest spend, there are significantly fewer research publications available. An analysis of these studies showed that researchers used a variety of variables to determine high spending markets, for example:

- The frequency of visits was used by Gyte and Phelps (1998), Jang, Morrison and O'Leary (2004), Kruger, Saayman and Saayman (2010) and Oppermann (1996).

- Age was used by Cini and Saayman (2014). 
- Travel motivation by Kruger, Viljoen and Saayman (2013) and Saayman and Saayman (2009).

Most other studies in this field were based on an analysis of visitor expenditure (see Craggs \& Schofield, 2006; Kruger, Saayman \& Saayman, 2010; Legoherel, 1998; Letho, Cai, O'Leary \& Huan, 2004; Mehmetoghu, 2007; Mok \& Iverson, 2000; Saayman \& Saayman 2006, 2009; Spotts \& Mahoney, 1991; Saayman, Van der Merwe \& Pienaar, 2009; Saayman, Van der Merwe \& Rossouw, 2011).

Sung, Morrison and O'Leary (2000) state that the use of a combination of variables to segment a market is preferred, rather than just using one. This article, therefore, adopts an approach that uses a combination of these variables which, to the best of the author's knowledge, has not been utilised previously. This approach not only identifies the big spending market segments and their characteristics, but also the extent to which an activity such as scuba diving can make an economic contribution to a town or region.

Tourist, or in this case, scuba diver spending is one of the most important variables in the analysis of a tourist destination because it directly determines not only the profitability of the sector but also the impact it has on regional economies (Frechtling, 2006). In addition, travel expenditure can vary from one segment to another, and one generally tends to find a combination of high, medium and low spenders in any tourist destination (Kruger \& Saayman, 2016), also called light, medium and high spenders by Spotts and Mahoney (1991). This research will therefore also identify different spending scuba diving markets at Portofino.

Besides differences in spending, are there differences in the characteristics of these high, medium and low spending markets? Research confirmed that high spenders compared to the medium and low segments tend to be (i) better educated (Snowball \& Willis, 2006; Woodside, Cook \& Mindale, 1987); (ii) they are older (Kruger, 2010; Saayman \& Saayman, 2006; Saayman et al., 2009), (iii) travel longer distances to a destination (Cannon \& Ford, 2002; Pouta, Neuvonen \& Sievänen, 2006), (iv) they earn more (Kruger, 2010; Saayman \& Saayman, 2006, 2012; Thrane, 2002), (v) they stem from other international markets or countries (Saayman \& Saayman, 2006), and (vi) they stay longer (Downward \& Lumsden 2004; Mehmetoglu, 2007; Mok \& Iverson, 2000; Thrane, 2002). While these characteristics seem to be consistent in distinguishing higher from lower spending markets, some are not so clear-cut. For example, concerning repeat visitors, Kruger, Botha and Saayman (2012), Shani, Polak and Shashar (2012) and Wang (2004) found that repeat visitors spend more. However, Alegre and Juaneda (2006), Kruger, Saayman and Ellis (2010), Lee, Lee, Bernhard and Yoon (2006), Oppermann (1996) and Petrick (2004) found the opposite trend. Svenssen et al. (2011) found no significant differences between first and repeat visitors.

Secondly, when it comes to group size, Saayman, Krugell and Van der Merwe (2007) found that large groups tend to spend more, while Kruger (2010), Saayman and Saayman (2006) and Svensson et al. (2011) found spending per person to be more for travellers in smaller groups. In one of the few studies that identified the determinants of spending of scuba divers, Saayman and Saayman (2012) found that behavioural variables exert a greater influence on spending behaviour of scuba divers than socio-demographic variables. In fact, their study also showed that divers who have a greater environmental awareness are bigger spenders than the rest.

\section{Method of research}

The method is discussed in three sections: (i) study area, (ii) questionnaire and survey, and (iii) statistical analysis.

\section{Study area}

Scuba diving tourism has witnessed unprecedented growth over the past twenty years, and one of the European Union's successful MPAs is Portofino in Italy. The Portofino MPA forms the study area for this research. The Portofino MPA lies on the northwestern coast of Italy, 13 nautical miles from Genoa on the Italian Riviera and it extends for $13 \mathrm{~km}$ along the Italian coastline. Twenty dive operators are operating in this MPA, some of them located as far away as Genoa. 
While the terrestrial protected area was already proclaimed in 1935 to prevent overdevelopment due to mass tourism, the MPA was established only in 1998 (Salmona \& Verardi, 2001). The MPA is divided into three zones, with different levels of restrictions. Zone A allows no mooring, sailing or anchoring, Zone $B$ allows no boats longer than 23.99 meters to sail in its waters, and Zone $\mathrm{C}$ allows sailing at right angles to the coast to allow boats to access anchoring points (Marina de Portofino, 2017). These zones are shown in Map 1 below. It stretches around the Portofino Peninsula, and underwater parts of the promontory have steep vertical walls and cliffs that create a unique environment together with the seafloor (Portofino Coast, 2017).

Three municipalities lie next to the MPA, namely Camogli, Portofino and Santa Margherita Ligure (see Map 1). On the borders of the MPA lie Recco and Rapallo. One activity that has seen an increase due to the MPA is, however, scuba diving, which may take place in Zones B and C. Currently, approximately 20 diving operators are active in the area, many of whom visit the MPA at regular intervals. Eight scuba diving operators are active in the Portofino - Santa Margherita area.

\section{Questionnaire and survey}

The questionnaire was developed to assess the socio-demographic and spending behaviour of scuba divers. Questions included gender, age, marital status, the level of education ( $1=$ school education, 5 = post-graduate degree), country of origin, size of travel group and spending on various items associated with scuba diving tourism. According to Stynes and White (2006), a more accurate estimation of visitor spending can be obtained by including various spending categories such as accommodation, food and beverage, transport, retail products, souvenirs and recreational activities. This approach was also followed in this research, and the following spending categories were included: scuba dives, scuba course, accommodation, transport, shopping, food and beverages, dive insurance, scuba equipment, hiring scuba gear, other recreational activities and other spending on goods and services.

In addition to the socio-demographics and spending behaviour, Musa et al. (2006) and Ong and Musa (2012) propose the inclusion of the level of diving experience of the scuba diver. Pabel and Coghlan (2011) also found that the level of experience plays an important

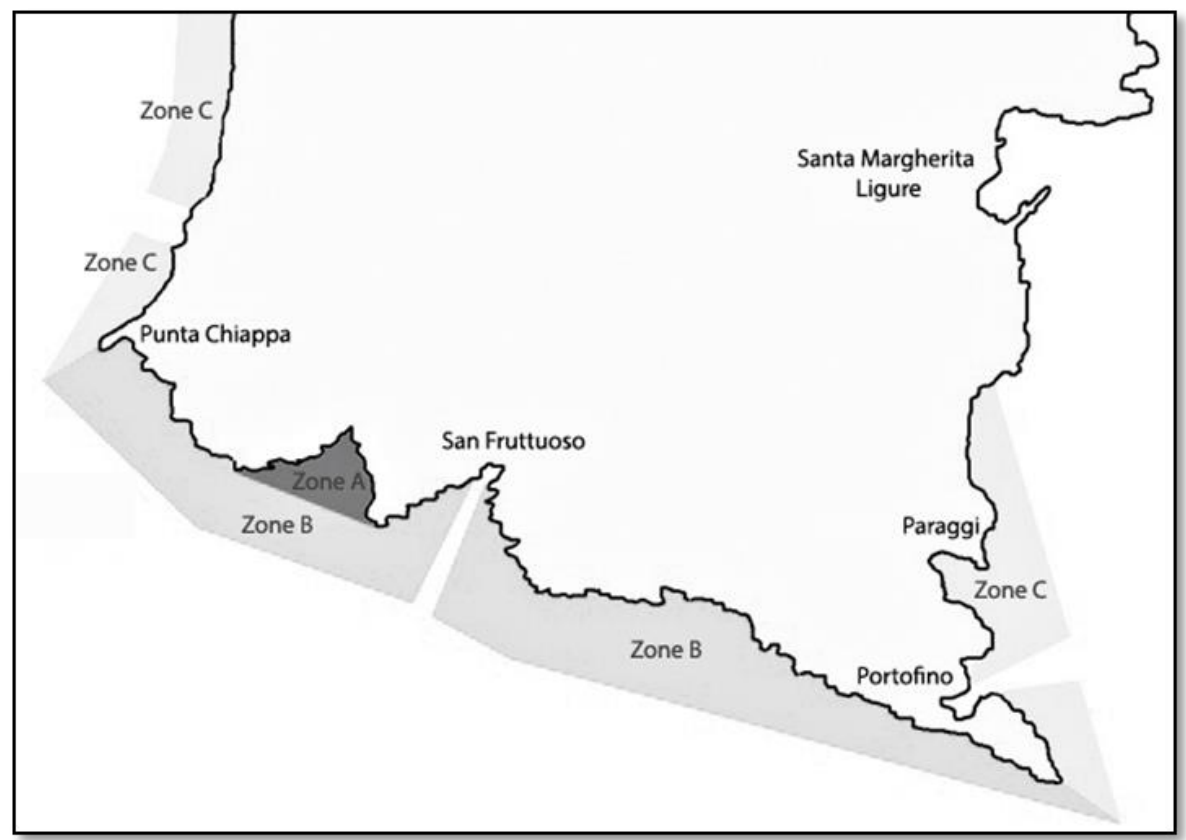

Map 1. The Portofino MPA 
role in the segmentation of divers. In this research, three questions were included to measure diving experience, namely the level of scuba diving course completed, the number of years the respondent has been scuba diving and the number of dives the respondent has completed. Since the level of scuba diving was an open-ended question, the levels had to be coded. The following framework was applied (see

http://www.scubatravel.co.uk/training/qualificati ons.html):

1 = Open water diver (OWD or beginner)

2 = Advanced open water diver (AOWD)

3 = Rescue diver and AOWD with "deep" specialisation

4 = Dive Master (or dive guide)

$5=$ Dive instructor.

The questionnaires were available in both Italian and English and were distributed by trained fieldworkers to scuba divers who had just completed dives at the Portofino MPA during June to August of 2016. Fieldworkers were assisted by diving operators in the following towns: Santa Margherita Ligure (6 operators), Recco (1 operator) and Rapallo (1 operator), who acted as both translators as well providing access to their facilities and diving clients. All divers who had completed a dive at the Portofino MPA during that time, using these operators, were asked to complete the questionnaire; however, participation always remained voluntary.

Altogether 732 completed questionnaires were received. With approximately 25000 dives per annum at the Portofino MPA, this amounts to a margin of error of approximately 3.5 with a $95 \%$ confidence level.

\section{Statistical analysis}

This paper focuses on the importance of scuba diving as a specific tourism activity in the MPA that creates income in the area. It is noteworthy that the Italian authorities would not support mass tourism and developments in the area, with the terrestrial protected area proclaimed to counter over development. Similarly, the MPA serves to protect the marine biodiversity of the area and therefore too much activity in the water is also not advisable. Is scuba diving, therefore, a worthwhile activity from a business and economic viewpoint?

28
To understand the economic impact that activity has on a local economy, it is firstly important to estimate the magnitude of spending - or the initial stimulus of economic activity. To this end, Stynes and White (2006) propose not only the inclusion of various spending categories (as mentioned above), but also the segmentation of visitors into distinct classes and the inclusion of information such as nights spent and size of the respondent's travel group. This research therefore not only analyses the spending patterns of scuba divers by means of descriptive analysis, but it also segments the divers into categories based on spending behaviour.

Since segments should be identifiable and distinct to be meaningful (Dolnicar, 2008), the variables included in the segmentation criteria are total spending (the most common variable used for expenditure-based segmentation and used by among others Craggs \& Schofield, 2006; Kruger, Saayman \& Saayman, 2010; Legoherel, 1998; Letho, Cai, O'Leary \& Huan, 2004; Mehmetoghu, 2007; Mok \& Iverson, 2000), as well as country of residence (used by Saayman \& Saayman, 2006) and level of diving experience (explained above and proposed by Musa et al., 2006; Ong and Musa, 2012, and Pabel and Coghlan, 2011). While spending is a continuous variable, level of diving experience is a nominal variable and country of residence, an ordinal variable. One segmentation technique that can handle both continuous and categorical variables simultaneously to sort cases into groups is two-step clustering.

Step one is called pre-clustering, and in this step, the matrix with the distances between cases is reduced in size when clusters of the original data are formed, which feeds into step two. Therefore, these clusters are used in step two and not the original data. In the second step, hierarchical clustering of the pre-clusters takes place.

Since some of the questionnaires had missing values, only the questionnaires that contained (i) complete spending data, (ii) a clear level of diving proficiency and (iii) country of origin, could be used in the clustering procedure. Therefore, all the analyses of the data is only done using the questionnaires that conformed 
to this criteria - a total of 484 unique respondents.

The differences between the clusters were investigated using Pearson's chi-square variables together with Cramer's V (as an indicator of effect size) for categorical and analysis of variance (ANOVA) and Bonferroni's posthoc test for continuous variables. While the assumption of an ANOVA is normality of the distribution of the errors, the analysis is not sensitive to the violation of normality in larger samples. However, violation of the assumption may lead to an increase in Type 1 error rate, while the Bonferroni post-hoc test control the Type 1 error rate (Field, 2009) and is therefore chosen as the suitable post-hoc test. Notwithstanding this, the results of the ANOVA were checked against the non-parametric Kruskal-Wallis test, and this test confirmed the ANOVA results. All analyses were performed using the IBM SPSS Statistics 24 software package.

\section{Results}

The results are discussed in two sections; firstly, the descriptive analysis to identify the spending pattern of the divers as well as the main socio-demographic characteristics, and secondly, the results of the segmentation with the differences between segments.

\section{Descriptive analysis}

Table 1 below provides summary statistics of the responses and Table 2 , the frequencies of the categorical variables. In each cased the complete sample is shown as well as an analysis of the Italian subsample and the subsample of respondents from other countries (i.e. non-locals). It is evident from the tables that the average age of respondents is 41.5 years, with both the Italian and the non-Italian sample showing a very similar age profile. Far more males than females form part of the diving community $(68.9 \%$ compared with $31.1 \%$, although the gender distribution is more equal under the non-Italian respondents and there are even slightly more female than male divers. Most of the divers (54.7\%) indicated that they are single, and more than $80 \%$ have post-school qualifications, with nonItalian divers also holding mostly post-graduate qualifications. Divers stay an average of 2.92 nights in the area, although non-Italian divers tend to stay longer - almost 5 nights. On average, the travel group consisted of approximately two people, regardless the origin of the respondents.

Tables 1 and 2 also show that the average diver is relatively proficient and had been scuba diving for more than 10 years, with 401 dives logged on average. The divers that originate from other countries have been diving slightly longer than their Italian counterparts and have also logged more dives in total, although the dives per year are quite similar. It is, therefore, evident that the average scuba diver in the Portofino MPA is not a beginner, but a more proficient and experienced diver. In fact, more than $60 \%$ of divers indicated that they had obtained a higher than advanced dive qualification (level 2) and here the Italian divers outperform their international counterparts with higher levels of qualifications achieved. Most scuba divers also indicated that they are not new to the MPA, with $82.1 \%$ of Italian and $36.4 \%$ of other divers being repeat visitors.

Table 1. Summary statistics

\begin{tabular}{lccccc}
\hline & Minimum & Maximum & $\begin{array}{c}\text { Mean: Total } \\
\text { respondents }\end{array}$ & $\begin{array}{c}\text { Mean: Italian } \\
\text { respondents }\end{array}$ & $\begin{array}{c}\text { Mean: Other } \\
\text { respondents }\end{array}$ \\
\hline Age & 13 & 91 & 41.55 & 41.61 & 41.00 \\
Nights Staying & 0 & 100 & 2.92 & 2.70 & 4.77 \\
People Paid For & 0 & 65 & 1.84 & 1.84 & 1.86 \\
Years Of Diving & 0 & 52 & 10.59 & 10.39 & 12.41 \\
Dives Logged & 1 & 7600 & 401.63 & 382.84 & 583.09 \\
Dives Per Year & 0 & 210 & 31.23 & 31.46 & 29.02 \\
\hline
\end{tabular}


Table 2. Frequency statistics

\begin{tabular}{lllll}
\hline & & $\begin{array}{l}\text { Total } \\
\text { respondents }\end{array}$ & $\begin{array}{l}\text { Italian } \\
\text { respondents }\end{array}$ & $\begin{array}{l}\text { Other } \\
\text { respondents }\end{array}$ \\
\hline Gender & Male & $68.9 \%$ & $70.9 \%$ & $48.9 \%$ \\
Marital Status & Female & $31.1 \%$ & $29.1 \%$ & $51.1 \%$ \\
& Married & $38.2 \%$ & $37.5 \%$ & $45.9 \%$ \\
& Separated & $5.9 \%$ & $6.3 \%$ & $2.7 \%$ \\
Education & Single & $54.7 \%$ & $55.3 \%$ & $48.6 \%$ \\
& Together & $1.1 \%$ & $1.0 \%$ & $2.7 \%$ \\
& Secondary School & $17.0 \%$ & $17.1 \%$ & $16.3 \%$ \\
& Diploma & $34.2 \%$ & $35.9 \%$ & $16.3 \%$ \\
Level Of Diving & Degree & $34.4 \%$ & $35.3 \%$ & $25.6 \%$ \\
& Post-Graduate & $14.0 \%$ & $11.5 \%$ & $39.5 \%$ \\
& Other & $0.4 \%$ & $0.2 \%$ & $2.3 \%$ \\
& Level 1 & $19.6 \%$ & $19.4 \%$ & $21.7 \%$ \\
& Level 2 & $19.2 \%$ & $17.8 \%$ & $32.6 \%$ \\
& Level 3 & $25.6 \%$ & $26.7 \%$ & $15.2 \%$ \\
& Level 4 & $16.3 \%$ & $16.4 \%$ & $15.2 \%$ \\
& Level 5 & $19.2 \%$ & $19.6 \%$ & $15.2 \%$ \\
\hline
\end{tabular}

Table 3. Origin of respondents

\begin{tabular}{llll}
\hline & Frequency & Valid Percent & $\begin{array}{l}\text { Cumulative } \\
\text { Percent }\end{array}$ \\
\hline Argentina & & & 0.2 \\
Austria & 1 & 0.2 & 0.6 \\
Belgium & 2 & 0.4 & 0.8 \\
Canada & 1 & 0.2 & 1.0 \\
France & 1 & 0.2 & 2.3 \\
Germany & 6 & 1.2 & 4.1 \\
Italy & 9 & 1.9 & 94.6 \\
Monaco & 438 & 90.5 & 94.8 \\
Norway & 1 & 0.2 & 95.2 \\
Peru & 2 & 0.4 & 95.5 \\
Portugal & 1 & 0.2 & 95.7 \\
South Africa & 1 & 0.2 & 96.1 \\
Spain & 2 & 0.4 & 96.5 \\
Sweden & 2 & 0.4 & 96.7 \\
Switzerland & 1 & 0.2 & 99.0 \\
UK & 11 & 2.3 & 99.8 \\
USA & 4 & 0.8 & 100.0 \\
Total & 1 & 0.2 & \\
\hline
\end{tabular}

Table 3 shows that approximately $90 \%$ of all divers at the Portofino MPA originate from Italy. The second largest source market of scuba divers is Switzerland, followed by Germany and France. Including divers from the UK, $8.4 \%$ of respondents were from European countries (excluding Italy), which implies that the Portofino MPA is a short- to medium-haul diving destination.
Concerning spending (see Table 4), the average scuba diver spends just over $€ 360$ on his/her scuba diving trip to the Portofino MPA. Italian divers spend significantly less than their international counterparts, which is expected since they stay for a shorter time, on average, and also incur less travel cost. Not surprisingly, most money is spent at the dive operator who administers the dives. The second most 
Table 4. Summary statistics of scuba diver spending (in Euro)

\begin{tabular}{lcrrrr}
\hline & Minimum & Maximum & $\begin{array}{l}\text { Mean: All } \\
\text { respondents }\end{array}$ & $\begin{array}{l}\text { Mean: } \\
\text { Italians }\end{array}$ & $\begin{array}{l}\text { Mean: Other } \\
\text { respondents }\end{array}$ \\
\hline Spending: Scuba Dives & 0 & 3800 & 82.73 & 74.08 & 165.11 \\
Spending: Dive Course/Training & 0 & 1500 & 51.33 & 51.79 & 46.96 \\
Spending: Accommodation & 0 & 2000 & 59.10 & 33.00 & 307.57 \\
Spending: Transportation & 0 & 2000 & 40.17 & 27.70 & 158.91 \\
Spending: Shopping & 0 & 1000 & 15.35 & 9.48 & 71.22 \\
Spending: Food \& Beverages & 0 & 2000 & 52.24 & 38.62 & 181.96 \\
Spending: Diving Insurance & 0 & 300 & 9.85 & 9.24 & 15.65 \\
Spending: Scuba Equipment & 0 & 3000 & 30.90 & 33.01 & 10.87 \\
Spending: Hiring Scuba Gear & 0 & 500 & 4.29 & 2.80 & 18.48 \\
Spending: Other Activities & 0 & 1000 & 4.85 & 0.73 & 44.02 \\
Spending: Other Expenses & 0 & 1000 & 10.74 & 6.50 & 51.04 \\
Spending: Total & 5 & 9500 & 361.55 & 286.96 & 1071.78 \\
\hline
\end{tabular}

Table 5. Cluster membership and mean spending

\begin{tabular}{llllll}
\hline & $\mathbf{N}$ & $\begin{array}{l}\text { \% } \\
\text { Combined }\end{array}$ & of & Mean & $\begin{array}{l}\text { Std. } \\
\text { Deviation }\end{array}$ \\
\hline Cluster & 1 & 114 & $23.6 \%$ & 196.14 & 286.401 \\
& 2 & 34 & $7.0 \%$ & 1679.21 & 1960.926 \\
& 3 & 78 & $16.1 \%$ & 215.05 & 318.430 \\
& 4 & 84 & $17.4 \%$ & 348.99 & 402.015 \\
& 5 & 92 & $19.0 \%$ & 360.22 & 488.342 \\
& 82 & $16.9 \%$ & 198.90 & 221.901 \\
& Combined & 484 & $100.0 \%$ & 361.55 & 718.119 \\
\hline
\end{tabular}

important spending categories are typical of any tourism activity - accommodation and food, and beverage spending. Rather than spending on shopping and other activities and goods, Italian scuba divers spend money on scuba equipment and additional training courses. In fact, approximately $47 \%$ of all spending goes directly towards the scuba industry, that is, the operators and supporting industries. This percentage is even higher for Italian divers (56\%), which is the primary diving market at the Portofino MPA.

\section{Segmentation results}

As indicated in section 3.3, this research uses two-step clustering to group scuba divers. The variables used in the clustering are both continuous (total spending) and categorical (origin country and level of diving). Initial Chisquare tests showed significant differences between the total spending as well as the level of divers from various countries of origin.

Figure 2 depicts the model summary, and it is evident that the procedure identified six distinct clusters as the optimal solution, according to the Schwarz Bayesian Criterion (BIC). The silhouette measure of cohesion and separation indicates that the cluster quality is excellent (above 0.75), implying that cases within a cluster are very similar and that they are very different from those in other clusters. 
Since total spending is the continuous variable used in the clustering process, the number of members in each of the six clusters, as well as the average total spending of each cluster, is shown in Table 5 . Cluster 1 has the most members, 114 or $23.6 \%$ of all the respondents who could be clustered. This cluster has the lowest average spending, even though merely less than $€ 200$. Cluster 2 has the least number of members - only $7 \%$ of the sample - and has the highest average spending at $€ 1679.21$. Cluster 6 is another low spending cluster, while the spending of clusters 4 and 5 are again close to one another, although still markedly less than that of cluster 2 .

To explore the differences between clusters, ANOVA and Bonferroni's post hoc results, Pearson's Chi-square and Cramer's V were assessed. Table 6 shows the ANOVA results, while Table 7 summarises the differences in the results that render the clusters distinct.

Table 6. ANOVA results indicating differences between clusters

\begin{tabular}{lrr}
\hline Item & F-statistic & Significance \\
\hline Age & 10.468 & 0.000 \\
Nights staying & 3.317 & 0.006 \\
People paid for & 0.405 & 0.845 \\
Years of diving & 17.420 & 0.000 \\
Dives logged & 16.943 & 0.000 \\
Scuba dives & 11.621 & 0.000 \\
Dive course/training & 4.633 & 0.000 \\
Accommodation & 19.296 & 0.000 \\
Transportation & 5.686 & 0.000 \\
Shopping & 10.013 & 0.000 \\
Food \& beverages & 13.242 & 0.000 \\
Diving insurance & 8.603 & 0.000 \\
Scuba & 5.182 & 0.000 \\
equipment/gear & 3.603 & 0.003 \\
Hiring scuba gear & 6.892 & 0.000 \\
Other activities & 1.629 & 0.151 \\
Other expenses &
\end{tabular}

For the continuous variables, the ANOVA indicated that there are significant differences for almost all the variables, except the number of people in the group for which the respondent is financially responsible, and the "other spending" category (see Table 6). Bonferroni's test showed where the differences lie, and these are subsequently highlighted: Concerning age, cluster 4 boasts the youngest divers who are significantly younger $(p<0.02)$ than the divers in all the other clusters (between 4 and 8 years younger on average), except cluster 5 . The divers in cluster 6 are, on average, the oldest, and are significantly older $(p<0.001)$ than those in clusters 4 and 5 (between 8 and 11 years older). Divers in cluster 2 stay significantly longer $(p<0.04)$ in the Portofino area than any other cluster (i.e. more than 5 nights on average longer), except cluster 3 .

The results also distinguish the proficiency of divers. Cluster 4 visitors had been diving for an average of only 2.1 years. This is significantly less $(p<0.003)$ than any of the other clusters who have been diving between 7 and 17 years longer, indicating more novice divers in this cluster. Divers in cluster 6 had been diving for an average of 19.4 years, which is significantly more $(p<0.001)$ than the divers in clusters 1 , 4 and 5 . The proficiency of divers in cluster 6 is further supported by the average number of dives logged - 1082 dives - which is significantly more $(p<0.007)$ than those in any other cluster, except cluster 2 (with an average of 680 dives logged). Divers in cluster 4 logged an average of only 10 dives, which is significantly less $(p<0.004)$ than those in clusters 2, 3 and 6 . This is followed by divers in cluster 5 (169 dives) and cluster 1 (182 dives), with significantly fewer $(p<0.03)$ dives logged than those in clusters 3 and 6 .

Concerning the differences in spending behaviour between clusters, the ANOVA results indicated that the differences are significant for all spending categories, except "other expenses" (seed Table 6). Divers in cluster 2 spend significantly more $(p<0.01)$ on diving activities and on scuba equipment than any of the other clusters, while divers in cluster 4 spend significantly more $(p<0.05)$ on diving courses than clusters 1,3 and 6 . Cluster 2 furthermore spends significantly more $(p \leq 0.001)$ on typical tourism goods and 
services, that is, accommodation, transport, food and beverages, shopping and other activities, than any other cluster. Divers in this cluster also spend the most on diving insurance (significantly more $(\mathrm{p}<0.05)$ than any other cluster), although divers in cluster 6 also spend significantly more $(p<0.05)$ on insurance than those in clusters 2, 4 and 5. Divers in cluster 2 furthermore spend significantly more ( $p \leq 0.01)$ on renting scuba gear than those in clusters 1 , 3 and 6.

Table 7 subsequently summarises the cluster characteristics and highlights the differences between the clusters, as identified by the various the various tests, and discussed above.
For the categorical variables, Cramer's $\mathrm{V}$ is an indication of the effect sizes. The effect size for the level of diving is very large (0.97), which is not surprising since this was one of the variables on which the clustering is based. The remaining effect sizes are quite small, although significant - for gender, it is 0.22 (Pearson's $\left.\chi^{2}=23.28\right)$; for marital status it is 0.134 (Pearson's $\chi^{2}=31.396$ ); for education it is 0.145 (Pearson's $\chi^{2}=40.243$ ) and for first time visitors to the MPA, it is 0.356 (Pearson's $\chi^{2}=58.26$ ). More than $90 \%$ of cluster 6 indicated that this was not their first visit to the MPA, followed closely by cluster 3 with $89 \%$ repeat visitors.

Table 7. Cluster differences

\begin{tabular}{|c|c|c|c|}
\hline & $\begin{array}{l}\text { CLUSTER 1: } \\
\text { Local rescue } \\
\text { divers (LRD) }\end{array}$ & $\begin{array}{c}\text { CLUSTER 2: } \\
\text { International big spending divers } \\
\text { (IBSD) }\end{array}$ & $\begin{array}{c}\text { CLUSTER 3: } \\
\text { Intracontinental dive } \\
\text { masters (IDM) }\end{array}$ \\
\hline Origin country & Italy & $\begin{array}{c}\text { Argentina; Austria; France (17\%); } \\
\text { Belgium; Germany (89\%); Italy } \\
\text { (2\%); Monaco; Peru; South Africa; } \\
\text { Spain (50\%); Switzerland (46\%); } \\
\text { UK(50\%); USA }\end{array}$ & $\begin{array}{l}\text { Canada; Italy (16\%); } \\
\text { Portugal; Spain (50\%); } \\
\text { Switzerland (18\%); UK } \\
\text { (25\%) }\end{array}$ \\
\hline Age & 42.4 & 43.3 & 45.8 \\
\hline Gender & $67.5 \%$ male & $55.9 \%$ female & $71.8 \%$ male \\
\hline Marital status & Single (58\%) & Single (48.4\%); Married (48.4\%) & Married (54.9\%) \\
\hline Education & $\begin{array}{l}\text { Diploma }(40.7 \%) \\
\text { Degree }(31.9 \%)\end{array}$ & $\begin{array}{c}\text { Degree (33.3\%); Post-Graduate } \\
(24.2 \%) \text {; Diploma (21.2\%); High } \\
\text { School (21.2\%) }\end{array}$ & $\begin{array}{l}\text { Diploma (33.8\%); Post- } \\
\text { Graduate }(21.2 \%) ; \\
\text { Degree }(21.2 \%) ; \text { High } \\
\text { School }(21.2 \%)\end{array}$ \\
\hline Nights & 1.9 & 7.6 & 4.3 \\
\hline First visit & No $(87 \%)$ & Yes $(54.5 \%)$ & No (89.2\%) \\
\hline Years diving & 9.6 & 13.4 & 14.2 \\
\hline Diving level & Rescue (level 3) & $\begin{array}{l}\text { OWD (level } 1 \text { - 32\%); Rescue (Level } \\
3 \text { - 29\%) Instructor (Level } 5 \text { - 32\%) }\end{array}$ & Dive master (level 4) \\
\hline Dives logged & 182 & 680 & 594 \\
\hline Scuba dives & $€ 48.67$ & $€ 433.15$ & $€ 68.45$ \\
\hline Dive course & $€ 45.83$ & $€ 64.71$ & $€ 29.42$ \\
\hline Accommodation & $€ 24.42$ & $€ 350.91$ & $€ 35.58$ \\
\hline Transportation & $€ 26.22$ & $€ 137.65$ & $€ 32.63$ \\
\hline Shopping & $€ 6.40$ & $€ 102.35$ & $€ 4.10$ \\
\hline Food \& beverages & $€ 26.34$ & $€ 250.15$ & $€ 37.51$ \\
\hline Diving insurance & $€ 5.06$ & $€ 44.41$ & $€ 5.77$ \\
\hline Scuba equipment & $€ 8.86$ & $€ 191.18$ & $€ 0.00$ \\
\hline Hiring scuba gear & $€ 0.92$ & $€ 18.68$ & $€ 0.01$ \\
\hline Other activities & $€ 0.33$ & $€ 50.74$ & $€ 0.00$ \\
\hline Other expenses & $€ 3.08$ & $€ 35.29$ & $€ 1.58$ \\
\hline
\end{tabular}


Table 7. Cluster differences (continue)

\begin{tabular}{|c|c|c|c|}
\hline & $\begin{array}{l}\text { CLUSTER 4: } \\
\text { New local divers } \\
\text { (NLD) }\end{array}$ & $\begin{array}{c}\text { CLUSTER 5: } \\
\text { Intracontinental } \\
\text { advanced divers (IAD) }\end{array}$ & $\begin{array}{c}\text { CLUSTER 6: } \\
\text { Local instructors (LI) }\end{array}$ \\
\hline Origin country & Italy & $\begin{array}{c}\text { France (83\%); Germany } \\
\text { (11\%); Italy (18\%); } \\
\text { Norway; Sweden, } \\
\text { Switzerland (36\%); UK } \\
\text { (25\%) }\end{array}$ & Italy \\
\hline Age & 35.0 & 38.4 & 46.5 \\
\hline Gender & $67.9 \%$ male & $62.6 \%$ male & $86.4 \%$ male \\
\hline Marital status & Single $(68.8 \%)$ & Single (56.4\%) & $\begin{array}{c}\text { Single }(48.1 \%) \text {; Married } \\
(42.9 \%)\end{array}$ \\
\hline Education & $\begin{array}{c}\text { Degree (44\%); } \\
\text { Diploma (35.7\%) }\end{array}$ & $\begin{array}{c}\text { Degree }(40.4 \%) \text {; Diploma } \\
(24.7 \%)\end{array}$ & $\begin{array}{c}\text { Diploma (39.5\%); Degree } \\
\text { (33.3\%); High School } \\
\text { (22.2\%) }\end{array}$ \\
\hline Nights & 2.3 & 2.0 & 2.3 \\
\hline First visit & No $(56.8 \%)$ & No $(77.5 \%)$ & No $(90.4 \%)$ \\
\hline Years diving & 2.1 & 7.3 & 19.4 \\
\hline Diving level & OWD (level 1) & AOWD (level 2) & Instructor (level 5) \\
\hline Dives logged & 10 & 169 & 1089 \\
\hline Scuba dives & $€ 47.79$ & $€ 69.41$ & $€ 49.12$ \\
\hline Dive course & $€ 117.26$ & $€ 56.73$ & $€ 0.67$ \\
\hline Accommodation & $€ 45.07$ & $€ 58.13$ & $€ 24.15$ \\
\hline Transportation & $€ 27.96$ & $€ 47.36$ & $€ 30.76$ \\
\hline Shopping & $€ 15.30$ & $€ 13.67$ & $€ 4.33$ \\
\hline Food \& beverages & $€ 28.19$ & $€ 60.35$ & $€ 35.73$ \\
\hline Diving insurance & $€ 2.92$ & $€ 2.72$ & $€ 21.18$ \\
\hline Scuba equipment & $€ 49.86$ & $€ 23.70$ & $€ 13.17$ \\
\hline Hiring scuba gear & $€ 5.83$ & $€ 9.21$ & $€ 0.00$ \\
\hline Other activities & $€ 1.67$ & $€ 4.46$ & $€ 0.39$ \\
\hline Other expenses & $€ 7.14$ & $€ 14.49$ & $€ 19.39$ \\
\hline
\end{tabular}

Based on the above, the clusters are labelled accordingly: CLUSTER 1: Local rescue divers (LRD), CLUSTER 2: International big spending divers (IBSD); CLUSTER 3: Intracontinental dive masters (IDM); CLUSTER 4: New local divers (NLD); CLUSTER 5: Intracontinental advanced divers (IAD) and CLUSTER 6: Local instructors (LI).

\section{Findings and implications}

Based on the results above, the first finding relates to the spending of scuba divers. The results show that the average scuba diver spends more than $€ 400$ on his/her scuba diving trip at the Portofino MPA (i.e. $€ 110$ per day).
This is similar to the research conducted by Graefe and Todd (2001) who found that the average diver in the USA spends between US $\$ 100-U S \$ 200$ per day. The importance of this is that almost $50 \%$ of this spending goes directly to the dive operators, that is, local businesses in Portofino. The fact that these services are provided locally limits the leakages from the local economy and therefore the scuba diving industry contributes towards both business development and income in the towns surrounding the MPA. Other large spending categories include typical tourism services, that is, accommodation, transport, food and beverages. 
This finding implies that destinations across the globe that focus on similar niche activities should ensure that key tourism-related services must be provided locally. This is a challenge, especially in developing countries where many of the tourism services are provided by "outsiders" and the local economy does not really benefit. Another important implication is the role that research plays in the regard because understanding the spending behaviour of tourists through research, aids in determining the extent to which the local economy benefit.

Secondly, this research identified six clusters, compared to most of the literature which identified a maximum of only 3 clusters, when a traditional-expenditure based segmentation approach is followed. While using the traditional expenditure-based segmentation may deliver a combination of high-, mediumand low spending clusters, these clusters are not always easily observable, which may pose difficulties when targeting specific market segments. Therefore, this research included both proficiency of diving as well as country of origin in identifying clusters. Based on this analysis, one high spending cluster was identified, and the divers in this cluster are mainly non-Italian and also travel from other continents to Europe (i.e. intercontinental) staying longer at the MPA. This confirms the notion by Saayman and Saayman (2006) that international or foreign tourists (divers) are the bigger spenders.

Also, the lower spending clusters are mainly Italian divers - local rescue divers, new local divers and local instructors - and reasons for lower spending include familiarity with local conditions, saving on accommodation, and hiring of equipment. Two of these are more proficient divers (rescue and instructors) who are also loyal divers at the MPA (87-90\% are return visitors), which is a market worth keeping. One Italian market is the young newcomers to diving, who spend more on diving courses and training than any of the other markets. This implies a three-pronged approach towards marketing, namely focusing on (i) the new local divers, (ii) the loyal more proficient local rescue and dive instructors, and (iii) new intercontinental big spending diver markets. However, dive operators cannot reach intercontinental markets on their budgets and the MPA could play a key role in assisting with international marketing efforts, thereby increasing the economic viability of the MPA.

Another implication from this research that could be applicable to other types of tourism and a lesson learnt from this research is the importance of offering a variety of services that have the potential to cater for different markets and their needs. This reduces the over-reliance on one market and, subsequently, provides a buffer to shocks that may occur in certain market segments.

The results of the analysis also showed that diving level indeed plays a key role and confirms the notion raised by Musa et al. (2006) and Ong and Musa (2012) that the level of competency needs to be considered when one deals with scuba divers. This is true not only for scuba diving, but also for other activities that require different levels of training, such as athletics, hunting, skiing, etc.

Finally, the analyses showed that two-step clustering with a combination of continuous and ordinal variables could deliver more detailed results that can inform marketing strategy better - not only for scuba diving tourism, but also for other forms of tourism. However, a sufficiently large sample is required.

\section{Conclusions}

The purpose of this research was to evaluate the importance of scuba divers as a source of tourism and income for the local economies surrounding the Portofino MPA. This was achieved by assessing four questions: (i) on what do scuba divers spend money? (ii) what influences their spending decisions? (iii) how can the tourism industry benefit from them, especially in resorts where divers seemingly have a significant impact? and (iv) are there specific segments of divers that are more worthwhile to pursue than others?

The results showed that the average diver spends more than $€ 110$ per day, with approximately $50 \%$ of this going directly to dive-specific expenses. Typical tourism-related activities, that is, accommodation, transport, 
food and beverages, are also important spending categories, indicating that local businesses indeed benefit from scuba diving activity in the MPA - not only operators, but also tourism businesses.

In answering the second and fourth question, this article contributes to the literature by identifying six clusters of divers based on their spending behaviour as well as diving proficiency and country of origin. It is clear from the results that local divers are lower and medium-spending clusters, while the big spending cluster consists of mainly international divers, many of whom travel a long distance to reach the MPA and therefore they also stay longer. This confirms the typical characteristics of big spending markets, that is, they travel further, stay longer, are more educated and stem from international markets.

For the region to benefit from scuba diving activity in the MPA, and also in response to question three posed above, the article showed that a combination of international divers and local divers pose the best option. While the local markets are ideal for sustainable scuba diving activity, since they are loyal visitors and there are also the newcomers (cluster 4), the intercontinental big spending market is currently the smallest. More effort should, therefore, be focused on attracting scuba divers in this cluster (cluster 2), which would require a team effort from both the MPA and the diving operators. Drawing international scuba divers to the Portofino MPA is also just one part of the problem - getting them to stay longer and diving more sites or including other activities for them, would increase spending and benefits to local businesses and economies.

From this research, future research expansions that should be explored include an economic impact analysis as well as an environmental impact analysis of scuba diving on the MPA and local economy. This is required to gain greater insight into the sustainability of scuba diving since the MPA is a natural resource that depends on proper conservation management. While the information gathered through the current questionnaire lends itself to the former, the environmental impact was not fully considered, and further information would need to be sourced before such an analysis can be undertaken. This is an aspect that needs further research and is a limitation of the current research.

\section{Acknowledgments}

The authors would like to thank the following people and institutions which made this research possible. Firstly, the fieldworkers and divers for completing the questionnaire. Secondly, the reviewers for their comments that helped in shaping this article. Finally, this study was funded by the Green Bubbles RISE project, H2020-MSCA-RISE-2014. The project has received funding from the European Union Horizon 2020 research and innovation programme under the Marie Sklodowska-Curie grant agreement No. 643712. This paper reflects only the authors' view. The Research Executive Agency is not responsible for any use that may be made of the information it contains.

\section{References}

Alegre, J., \& Juaneda, C. (2006). Destination loyalty: Consumers' economic behavior. Annals of Tourism Research, 33, 684-706.

Cannon T. F., \& Ford J. (2002). Relationship of demographic and trip characteristics to visitor spending: an analysis of sport travel visitors across time. Tourism Economics, 8 , 263-271.

Catlin, J., Jones, T., Norman, B., \& Wood, D. (2010). Consolidation in a wildlife tourism industry: the changing impact of whale shark tourist expenditure in the Ningaloo coast region. International Journal of Tourism Research, 12, 134-148.

Cini, F., \& Saayman, M. (2014). Which age group spends the most in a national park? Koedoe, 56(2), 1-8.

Craggs, R., \& Schofield, P. (2006). Expenditure segmentation and visitor profiling: regenerating the quays in Salford, UK. Salford: University of Salford.

Dolnicar, S. (2002). A review of data-driven market segmentation in tourism. Journal of Travel and Tourism Marketing, 12(1), 1-22.

Downward, P., \& Lumsdon, L. (2004). Tourism transport and visitor spending: a study in the North York Moors National Park, UK. 
Journal of Travel Research, 42(4), 415420.

Dudley, N. (2008). Guidelines for applying protected area management categories. Gland, Switzerland: IUCN.

Du Plessis, E., \& Saayman, M. (2017). What makes scuba diving operations successful: The case study of Portofino, Italy. Paper presented at the Annual Conference of the International Association of Scientific Experts in Tourism, 28 ${ }^{\text {th }}-31^{\text {st }}$ August 2016, Malta.

Ekonomou, G., Neofitou, C., \& Matsiori, S. (2014). An investigation into the market segments of coastal visitors: evidence from Greece. E-review of Tourism Research, 11(3), 1-33.

Field, A. (2009). Discovering Statistics using SPSS, $3^{\text {rd }}$ edition. London: Sage.

Frechtling, D. C. (2006). An assessment of visitor expenditure methods and models. Journal of Travel Research, 45(1), 26-35.

Greafe A. R., \& Todd, S. I. (2001). Economic impacts of scuba diving on New York's Great Lakes. Proceedings of the North Carolina Coastal Plains Paddle Trails Initiative Conference, Fall 2001, Seven Springs, NC.

Gyte, D., \& Phelps, A. (1998). Patterns of destination repeat business: British tourists in Mallorca, Spain. Journal of Travel Research, 28(1), 24-28.

Harriott, V. J. (2002). Marine tourism impacts and their management on the Great Barrier Reef (No. 46). Townsville: CRC Reef Research Centre.

Jang, S., Morrison, A. M., \& O'Leary, J.T. (2004). A procedure for target market selection in tourism. Journal of Travel and tourism Marketing, 16(1), 17-31.

Johnson, R. L., \& Moore, E. (1993). Tourism impact estimation. Annals of Tourism Research, 20(2), 279-288.

Kruger, M. (2010). A critical evaluation of market segmentation at national arts festivals in South Africa. PhD thesis. NorthWest University, South Africa. URL: https://repository.nwu.ac.za/bitstream/handl e/10394/6283/kruger m.pdf?sequence $=1$ \& sAllowed=y (Accessed on 11.01.2017)

Kruger, M., Saayman, M., \& Ellis, S. M. (2010). Does loyalty pay? First-time versus repeat visitors at a national arts festival. Southern African Business Review, 14(1), 79-104.

Kruger, M., Saayman, M., \& Saayman, A. (2010). Expenditure-based segmentation of visitors to the Tsitsikamma National Park. Acta Commercii, 10(1), 137-149.

Kruger, M., Botha, K., \& Saayman, M. (2012). The relationship between visitor spending and repeat visits: an analysis of spectators at the Old Mutual Two Oceans Marathon. Acta Commercii, 12(1), 108-122.

Kruger, M., Viljoen, A., \& Saayman, M. (2013). Who pays to view wildflowers in South Africa? Journal of Ecotourism, 12(3), 146164.

Kruger, M., \& Saayman, M. (2016). Are you willing to pay more for the arts? Journal of Economic and Financial Sciences, 9(2), 392-408.

Lee, C., Lee, Y., Bernhard, B., \& Yoon, Y. (2006). Segmenting casino gamblers by motivation: a cluster analysis of Korean gamblers. Tourism Management, 27(5), 856-866.

Leeworthy, V. R., Bowker J. M., Hospital J. H., \& Stone E. A. (2005). Projected participation in marine recreation: 2005 \& 2010. Washington, DC: NOAA, SEA Division, National Ocean Service.

Legoherel P. (1998). Towards a market segmentation of the tourism trade: expenditure levels and consumer behaviour instability. Journal of Travel Research, 7(3), 19-39.

Letho, X. Y., Cai, L. A., O'leary, J. T., \& Huan, T. (2004). Tourist shopping preferences and expenditure behaviours: the case of the Taiwanese outbound market. Journal of Vacation Marketing, 10, 320-332.

Marina de Portofino. (2017). Portofino \& Surroundings. URL: http://www.marinadiportofino.com/en/portofi no-and-surroundings/ (Accessed on 10.01.2017).

Mehmetoglu, M. (2007). Nature-based tourists: the relationship between their trip expenditures and activities. Journal of Sustainable Tourism, 15(2), 200-215.

Mok, C., \& Iverson, T. J. (2000). Expenditurebased segmentation: Taiwanese tourists to Guam. Tourism Management, 28, 299-305.

Musa, G., Kadir, S. L. S. A., \& Lee, L. (2006). Layang Layang: An empirical study on 
scuba divers' satisfaction. Tourism in Marine Environments, 2, 89-102.

Ong, T. F., \& Musa, G. (2012). Examining the influences of experience, personality and attitude on SCUBA divers' underwater behaviour: A structural equation model. Tourism Management, 33(6), 1521-1534.

Oppermann, M. (1996). Visitation of tourism attractions and tourist expenditure patterns: repeat versus first-time visitors. Asia Pacific Journal of Tourism Research, 1(1), 61-68.

Pabel, A., \& Coghlan, A. (2011). Dive market segments and destination competitiveness: A case study of the Great Barrier Reef in view of changing reef ecosystem health. Tourism in Marine Environments, 7(2): 5566.

Park, D-B., \& Yoon, Y-S. (2009). Segmentation by motivation in rural tourism: A Korean case study. Tourism Management, 30(1), 99-108.

Petrick, J. F. (2004). First timers' and repeaters' perceived value. Journal of Travel Research, 43(1), 29-39.

Pouta, E., Neuvonen, M., \& Sievänen, T. (2006). Determinants of nature trip expenditures in Southern Finland: implications for nature tourism development. Scandinavian Journal of Hospitality and Tourism, 6(2), 118-135.

Portofino Coast. (2017). Elegance \& hospitality in the Italian Riviera. URL: http://www.portofinocoast.it/en/Default.aspx (Accessed on 11.01.2017).

Russi, D., Pantzar, M., Kettunen, M., Gitti, G., Mutafoglu, K., Kotulak, M., \& Ten Brink, P. (2016). Socio-economic benefits of the EU marine protected areas. London: Institute for European Environmental Policy (IEEP).

Saayman, M., Krugell, W., \& Van Der Merwe, P. (2007). The determinants of spending by biltong hunters. South African Journal of Economics and Management Sciences, 10(2), 184-194.

Saayman, M., Van Der Merwe, P., \& Pienaar, J. (2009). Expenditure-based segmentation of tourists to the Kruger National Park. Acta Academica, 41(3), 107-127.

Saayman, M., \& Saayman, A. (2006). Does the location of arts festivals matter for the economic impact? Papers in Regional Science, 85(4), 569-584.
Saayman, M., \& Saayman, A. (2009). Why travel motivation and socio-demographics matter in managing a national park. Koedoe, 51(1), 1-9.

Saayman, M., Van der Merwe, P., \& Rossouw, R. (2011). The impact of hunting for biltong purposes on the SA economy. Acta commercii, 11(1), 1-12.

Saayman M., \& Saayman A. (2012). Determinants of spending: an evaluation of three major sporting events. International Journal of Tourism Research, 14(2), 124138.

Saayman, M., \& Seymour, K. (2012). A social and environmental impact analysis of scuba diving activities at Sodwana Bay. Potchefstroom: Tourism Research in Economic Environs and Society, North West University.

Sakellariadou, F. (2014). The concept of marine ecotourism: case study in a Mediterranean island. International Journal of Climate Change: Impacts \& Responses, 6(1), 1-33.

Salmona, P., \& Verardi, D. (2001). The marine protected area of Portofino, Italy: A difficult balance. Ocean \& Coastal Management, 44(1-2), 39-60.

Schuhmann, P., Casey J. \& Oxenford, H. A. (2008). The value of coral quality to scuba divers in Barbados. Proceedings of the 11th International Coral Reef Symposium, pp. $1149-1152, \quad 7^{\text {th }}-11^{\text {th }}$ July, Ft. Lauderdale, Florida.

Shani, A., Polak, O., \& Shashar, N. (2012). Artificial reefs and mass marine ecotourism. Tourism Geographies, 14(3), 361-382.

Snowball, J. D., \& Willis, K. G. (2006). Estimating the marginal utility of different sections of an arts festival: the case of visitors to the South African National Arts Festival. Leisure Studies, 25(1), 43-56.

Spotts, D. M., \& Mahoney, E. M. (1991). Segmenting visitors to a destination region based on the volume of their expenditures. Business Research Division, 29(4), 42-31.

Stynes, D. J., \& White, E. M. (2006). Reflections on measuring recreation and travel spending. Journal of Travel Research, 45(1), 8-16.

Sung, H.Y., Morrison, A.M., \& O'Leary, J.T. (2000). Segmenting the adventure travel 
market by activities: From the North American Industry Providers' Perspective. Journal of Travel and Tourism Marketing, 9(4): 1-19.

Svensson, B., Moreno, P., \& Martin, D. (2011). Understanding travel expenditure by means of market segmentation. The Service Industries Journal, 31(10), 16831698.

Thrane, C. (2002). Jazz Festival visitors and their expenditures: linking spending patterns to musical interest. Journal of Travel Research, 40(3), 281-286.

Tyrrell, T. J., \& Johnston, R. J. (2006). The economic impacts of tourism: a special issue. Journal of Travel Research, 45(1), 37.

Wang, D. (2004). Tourist behaviour and repeat visitation to Hong Kong. Tourism Geographies, 6(1), 99-118.

Wilks, J., \& Davis, R. J. (2000). Risk management for scuba diving operators on Australia's Great Barrier Reef. Tourism Management, 21(6), 591-599.
Woodside, A.G., Cook, V.J., \& Mindak, W. (1987). Profiling the heavy traveller segment. Journal of Travel Research, 25(3): 9-15.

Wilton J. J., \& Nickerson, N. P. (2006). Collecting and using visitor spending data. Journal of Travel Research, 45(1), 17-25.

World Adventure Divers. (2016). Portofino Marine Protected Area Map. URL: https://worldadventuredivers.com/2016/07/ 16/scuba-diving-in-portofinoitaly/img_20140607_0013-1024x744/ (Accessed on 31.03.2017).

Wood, D., \& Glasson, J. (2006). Giving the environment a voice: the transformational potential of valuing tourism in sensitive natural environments: the case of the Ningaloo coastal region, Western Australia. Journal of Planning Practice and Research, 20(4), 391-407. 